\title{
Morpho-functional evaluation of small bowel using wireless motility capsule and video capsule endoscopy in patients with known or suspected Crohn's disease: pilot study
}

Authors

Institutions
Diana Yung ${ }^{1}$, Sarah Douglas ${ }^{1}$, Anthony R. Hobson ${ }^{2}$, Andry Giannakou ${ }^{3}$, John N. Plevris ${ }^{1}$, Anastasios Koulaouzidis ${ }^{1}$

${ }^{1}$ Royal Infirmary of Edinburgh - Centre of Liver \& Digestive Disorders, Edinburgh, UK

2 The Functional Gut Clinic - The Functional Gut Clinic, London, UK

${ }^{3}$ Open University of Cyprus - Faculty of Economics and Management, Nicosia, Cyprus submitted

19. September 2015 accepted after revision 4. January 2016

\section{Bibliography}

DOI http://dx.doi.org/

10.1055/s-0042-100718

Published online: 22.3.2016

Endoscopy International Open 2016; 04: E480-E486

(c) Georg Thieme Verlag KG

Stuttgart - New York

E-ISSN 2196-9736

\section{Corresponding author}

\section{Diana Yung}

The Royal Infirmary

of Edinburgh

51 Little France Crescent

Edinburgh EH16 4SA

UK

Fax: +077-895-88408

diana.e.yung@gmail.com
Background and study aims: SmartPill ${ }^{\circledR}$ (Given Imaging Corp.,Yoqneam,Israel) is an ingestible, non-imaging capsule that records physiological data including contractions and $\mathrm{pH}$ throughout the gastrointestinal tract. There are scarce data looking at SmartPill ${ }^{\circledR}$ assessment of patients with known/suspected small-bowel Crohn's Disease (CD). This pilot study aims to investigate feasibility and safety of SmartPill ${ }^{\circledR}$ to assess gut motility in this group.

Patients and methods: Over 1 year, patients with known/suspected CD, referred for small-bowel capsule endoscopy (SBCE), were invited to participate and 12 were recruited ( 7 female, 5 male, mean age $44.2 \pm 16.6$ years). They underwent hydrogen breath test to exclude small-bowel bacterial overgrowth, patency capsule (Agile ${ }^{\circledR}$ ), and provided stool samples for fecal calprotectin (FC). Patients ingested PillCam ${ }^{\circledR}$ SB2 and SmartPill ${ }^{\circledR} 4$ hours apart. Using unpublished data, 33 healthy controls also were identified for the study. $P<$ 0.05 was considered statistically significant.

\section{Introduction}

$\nabla$

The wireless motility capsule (WMC) (SmartPill ${ }^{\circledR}$; Given Imaging Corp., Yoqneam, Israel) is a singleuse, ingestible device $[1,2]$. With dimensions $26.8 \times 11.7 \mathrm{~mm}$, it is slightly bulkier than its imaging counterpart (PillCam ${ }^{\circledR}$ SB Medtronic, Minnesota, USA). SmartPill ${ }^{\circledR}$ records intraluminal $\mathrm{pH}$, pressure and temperature as it is propelled through the gastrointestinal tract. Hence, the WMC is capable of providing gut motility parameters (i.e. gastric transit time [GTT], small-bowel transit time [SBTT], colonic transit time [CTT] and whole gut transit time [WGTT]) noninvasively. The American and European Neurogastroenterology \& Motility Societies recommend the use of WMC to assess suspected gastroparesis, suspected small-bowel (SB) dysmotility and/or CTT in chronic constipation [3].
Results: Of the 12 patients enrolled, 10 underwent complete Smartpill ${ }^{\circledR}$ examination (1 stomach retention, 1 dropout). Pillcam ${ }^{\circledR}$ was complete in 10 ( 1 dropout, 1 stomach retention). Mean fecal calprotectin was $340 \pm 307.71 \mathrm{mcg} / \mathrm{g}$. The study group had longer transit times and lower gut motility index than did the controls. The difference in motility appears to be statistically significant $(P<0.05)$. Longer transit times for SmartPill ${ }^{\circledR}$ (not statistically significant) may have been due to different specifications between the capsules. Limitations included transient Smartpill ${ }^{\circledR}$ signal loss (5/10 studies).

Conclusions: This is the first pilot to attempt combining SBCE and SmartPill ${ }^{\circledR}$ to assess small-bowel CD. Data on motility in CD are scarce. Multimodal information can provide a clearer clinical picture. Despite concerns about capsule retention in $C D$ patients, SmartPill ${ }^{\circledR}$ seems safe for use if a patency capsule is employed beforehand.

Data are scarce on the motility patterns in patients with known or suspected Crohn's disease (CD). Furthermore, the use and clinical validity of the WMC has not been evaluated in this patient group. It is envisaged that future wireless investigation platforms for the digestive tract will be multimodal and versatile, and therefore able to incorporate imaging information with physiological or biochemistry data such as fecal calprotectin (FC), hemoglobin and gas constituents of the gastrointestinal tract. Such combination data could be useful in the investigation and management of patients with $\mathrm{CD}$. For instance, orocecal transit time has been found to be prolonged in CD patients for various reasons including SB bacterial overgrowth (SBBO) whereas SBTT may conversely be shortened in $C D$ patients following ileocecal resection; this would affect absorption of medications and should ideally be taken into 
account during drug design [4]. Therefore, we designed a pilot study to investigate whether WMC examination is feasible and safe in the assessment of gut motility in patients with known or suspected $\mathrm{CD}$, and its utility compared to conventional video capsule endoscopy.

\section{Patients and methods \\ $\nabla$}

\section{Patient recruitment and study protocol}

Consecutive patients with known or suspected CD (FC>200 $\mu \mathrm{g} /$ g), referred for SB evaluation with small-bowel capsule endoscopy (SBCE), were invited to participate in this study. The inclusion \& exclusion criteria of the study are summarized in - Table1. Patients who accepted the invitation and consented to participate were invited for a lactulose hydrogen breath test for exclusion of SB bacterial overgrowth (SBBO) and were provided with a kit for stool sample collection and FC measurement (CALPROLAB $^{\text {TM }}$ ELISA (ALP), Calpro AS, Lysaker, Norway; reference range $<50 \mu \mathrm{g} / \mathrm{g}$ ). Those with a positive breath test, indicating SBBO, were excluded. Patients with negative SBBO breath test were invited to return a stool specimen and attend for a SB patency check with the AGILE ${ }^{\circledR}$ capsule (Given Imaging Corp., Yoqneam, Israel).

The detailed flowchart of the study design is presented in - Fig. 1. Patients ingested the PillCam ${ }^{\circledR}$ SB, followed 4 hours later, by the SmartPill ${ }^{\circledR}$. The technical characteristics of the two capsules used (PillCam ${ }^{\circledR}$ SB and SmartPill ${ }^{\circledR}$ ) are detailed in $\bullet$ Table 2.

\section{Data collection}

Data were downloaded from the recorders to the relevant workstations and analyzed using proprietary software $\left(R A P I D^{\circledR}\right.$ for PillCam ${ }^{\circledR}$ SB and semi-automated pressure analysis software, MotiliG ${ }^{\circledR}$ [Given ${ }^{\circledR}$ Imaging Corp] for SmartPill ${ }^{\circledR}$ ). For the latter, results are presented in both graphical and statistical forms. PillCam ${ }^{\circledR}$ data include gut transit times and SB findings. Inflammation levels were quantified using the Lewis score (LS), which has been devised to objectively report SB inflammation in SBCE. SmartPill ${ }^{\circledR}$ data examined in this study were $\mathrm{pH}$, transit times (GTT, SBTT, CTT and WGTT) and motility index (MI) per segment, where $\mathrm{MI}=\mathrm{Ln}$ (sum of pressure amplitudes $\times$ number of contractions +1 ). The data acquired from the study group were compared to historical controls (healthy individuals with no known pathology obtained from unpublished data), used to establish the normal range for segmental and total gut transit times.

\section{Statistical analysis}

Microsoft Excel ( ${ }^{(} 2015$ Microsoft) and StatsDirect (StatsDirect Ltd, Altrincham, UK) software were used for statistical analysis. A two-tailed Mann-Whitney U test was used for comparison of the study and control groups. Linear regression was used to establish any correlation between motility indices and FC or LS. $P$ values $<0.05$ were considered statistically significant.

The study was supported by a defined grant by Given ${ }^{\circledR}$ Imaging Ltd (ESGE- Given ${ }^{\circledR}$ Imaging Research grant 2011) and approved by the local ethics committee (ref. 12/SS/0013).
Table 1 Inclusion and Exclusion Criteria.

$\begin{array}{ll}\text { Inclusion criteria } & \text { Exclusion criteria } \\ \text { - Age }>18 \text { years } & \text { - Pregnancy or lactation } \\ \text { - Known diagnosis of CD, being } & - \text { Swallowing difficulties or frailty } \\ \text { referred for (re-) assessment of } & - \text { Known SB strictures } \\ \text { extent \& severity of SB inflam- } & \text { - Pacemaker/ICD in situ } \\ \text { mation } & - \text { Psychiatric history } \\ \text { Suspected CD with FC } & - \text { Prior upper gastrointestinal } \\ >200 \mu \mathrm{g} / \mathrm{g} & \text { tract surgery (other than end- } \\ & \text { to-end anastomosis) } \\ & - \text { Known DM or other cause of } \\ & \text { metabolic gastroparesis } \\ & - \text { Pts on codeine/morphinoids } \\ & \text { unable or unwilling to stop } \\ & \text { them prior to the study } \\ & - \text { Lactose intolerance or egg } \\ & \text { allergy (for PC) } \\ - & \text { Positive hydrogen breath test } \\ - & \text { History of functional symptoms } \\ & \text { e. g. cyclical vomiting, irritable } \\ & \text { bowel syndrome }\end{array}$

Abbreviations: CD, Crohn's disease; DM, diabetes mellitus; FC, fecal calprotectin; ICD, implantable cardioverter defibrillator; PC, patency capsule; SB, small-bowel; pts, patients

Table 2 Comparison between specifications of PillCam ${ }^{\circledR}$ SB2 and SmartPill ${ }^{\circledR}$.

\begin{tabular}{|lll|}
\hline Specifications & PillCam $^{\circledR}$ SB2 & SmartPill $^{\circledR}$ \\
\hline Length $(\mathrm{mm})$ & 26 & 26 \\
\hline Diameter $(\mathrm{mm})$ & 11 & 13 \\
\hline Battery life & $8 \mathrm{~h}$ & 5 days \\
\hline $\begin{array}{l}\text { Mode of data } \\
\text { transmission }\end{array}$ & $\begin{array}{l}\text { Ultra-high frequency band radio } \\
\text { telemetry }\end{array}$ & $\begin{array}{l}\text { Radiofrequen- } \\
\text { cy-based }\end{array}$ \\
\hline
\end{tabular}

\section{Results}

Over a 12-month period (2012), 19 patients were recruited. Three patients were excluded because their previous history included a known strong functional component to their symptoms that could affect gut motility independently of $C D$, including irritable bowel syndrome, chronic idiopathic intestinal pseudo-obstruction and cyclic vomiting. Another four patients, referred for SBCE on suspicion of CD, were also excluded because their FC levels were $<200 \mu \mathrm{g} / \mathrm{g}$. Twelve patients completed the study ( $7 \mathrm{fe}-$ male/5 male; mean age $44.2 \pm 16.6$ years). Fig. 2 shows the number of patients recruited, dropouts, and complete/incomplete data sets obtained. Clinical characteristics and per patient study results are tabulated in detail in Table 3 . The differences in the motility of the study group vs. the control group are depicted in Table4. Patients in our study had longer transit times and significantly lower gut motility when compared to the control group, $\bullet$ Fig. 3 and $\odot$ Fig. 4.

The motility index (MI) in the stomach, SB and colon was significantly lower in patients with $\mathrm{CD}$, as compared with controls, and this was statistically significant $(\mathrm{P}<0.05)$ for all motility indices measured throughout the gut. The total transit time for the WMC was longer compared with the SBCE, which could be attributed to the differences in the capsules' specifications as detailed in Table $2[1,5,6]$ and the difference in capsule density, $\bullet$ Fig. 5 $[7,8]$. The distribution of WGTT, FC and LS for those study sub- 


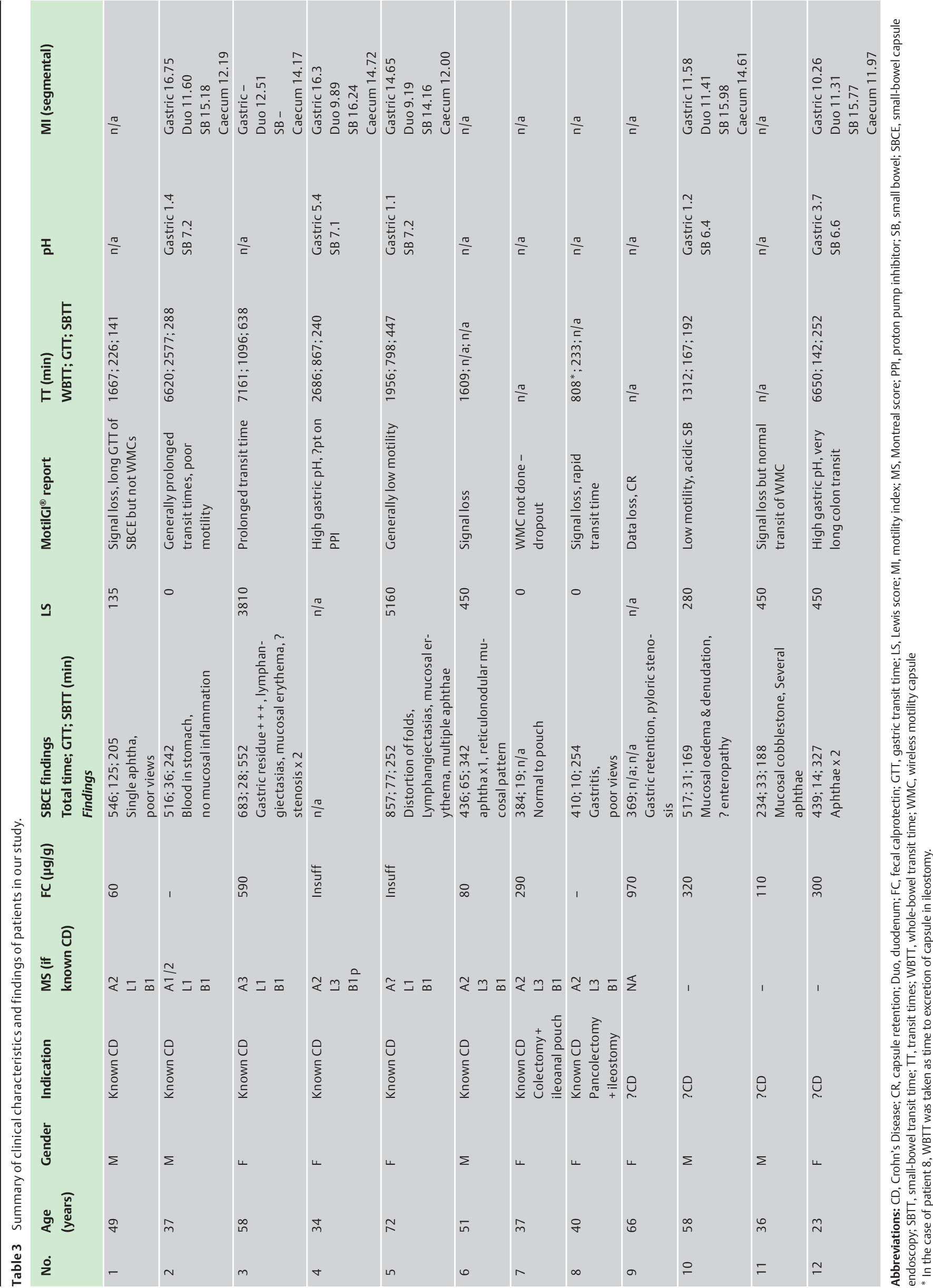




\begin{tabular}{|c|c|c|c|}
\hline & Patients & Controls & $P$ values \\
\hline Number & 12 & 33 & \\
\hline Gender & $7 \mathrm{~F}, 5 \mathrm{M}$ & $15 \mathrm{~F}, 18 \mathrm{M}$ & \\
\hline Average Age $\pm S D$ & $44.25 \pm 16.66$ years & $40.85 \pm 16.28$ years & \\
\hline FC $(\mu g / g)$ & $340 \pm 307.71(n=8)$ & $\mathrm{n} / \mathrm{a}$ & \\
\hline LS & $1073.5 \pm 1835.5(n=10)$ & $\mathrm{n} / \mathrm{a}$ & \\
\hline GTT (min) & $763.25 \pm 821.47(n=8)$ & $249.61 \pm 167.47$ & 0.09 \\
\hline SBTT (min) & $314 \pm 171.99(n=7)$ & $288.81 \pm 107.74$ & 0.89 \\
\hline WBTT (min) & $3385.44 \pm 2621.03(n=9)$ & $1988.67 \pm 972.99$ & 0.82 \\
\hline Gastric pH & $2.56 \pm 1.92(n=5)$ & $1.64 \pm 0.89$ & 0.35 \\
\hline SB pH & $6.9 \pm 0.37(n=5)$ & $7.16 \pm 0.45$ & 0.17 \\
\hline Gastric MI & $13.91 \pm 2.88(n=5)$ & $52.00 \pm 32.68$ & 0.002 \\
\hline Duodenal MI & $10.99 \pm 1.22(n=6)$ & $90.27 \pm 76.50$ & 0.0001 \\
\hline SB MI & $14.55 \pm 1.92(n=5)$ & $122.48 \pm 65.90$ & 0.0004 \\
\hline Cecal MI & $13.28 \pm 1.35(n=6)$ & $108.58 \pm 121.10$ & 0.0006 \\
\hline
\end{tabular}

Table 4 Comparison of results from our patients vs controls. For our patients, some results were not available for all patients, therefore $\mathrm{N}$ is given where $\mathrm{n}=$ number of patients for whom results were available.

Abbreviations: FC, fecal calprotectin; GTT, gastric transit time; LS, Lewis score;

MI, motility index; SB, small bowel; SBTT, small-bowel transit time; WBTT, whole-bowel transit time

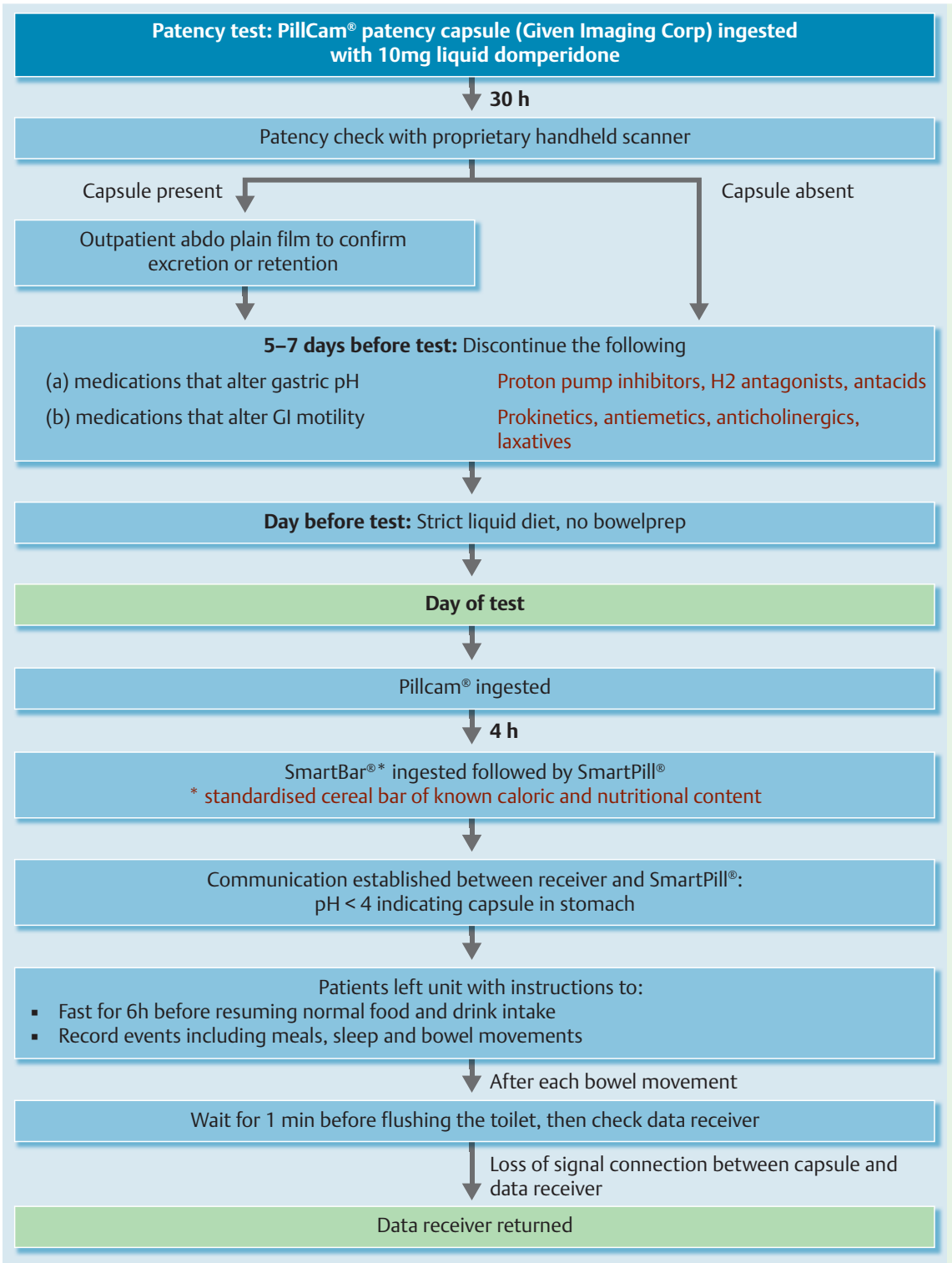

Fig. 1 Summary of study protocol. 
19 patients recruited over 1 year:

Consecutive patients referred for SBCE with the indications of $\mathrm{CD}$ or ?CD

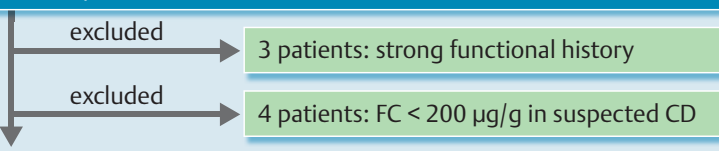

12 included in final study

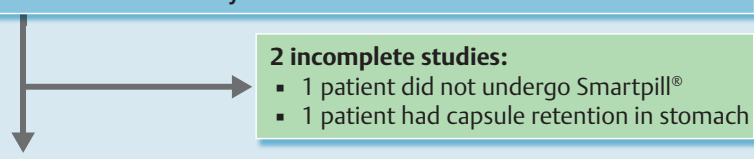

10 completed studies as per protocol

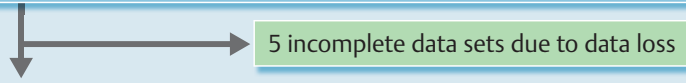

5 complete studies with full data sets

Fig. 2 Recruitment process for this study. jects for whom the data were available is presented in $\bullet$ Fig.6a.

- Figs. $6 \mathrm{~b}$ and $\mathbf{6 c}$ show the linear regression between MI/FC and $\mathrm{MI} / \mathrm{LS}$, respectively.

\section{Discussion}

This pilot study is the first to attempt dual use of SBCE and WMC in assessment of patients with known or suspected CD. Currently, diagnosing $C D$ requires a clinical evaluation and a combination of endoscopic, histological, radiological, and/or biochemical investigations [9]. To date, the value of SBCE in the investigation of CD has already been established [10]. A previous study [11], in which cine magnetic resonance enterography (MRE) was employed in addition to the regular MRI protocol, found that imaging areas of altered gut motility helped to detect more CD-specific findings. Other studies have shown that CD is associated with delayed gastric emptying, possibly due to inflammation [12].

Therefore, addition of motility data in this setting could be of use

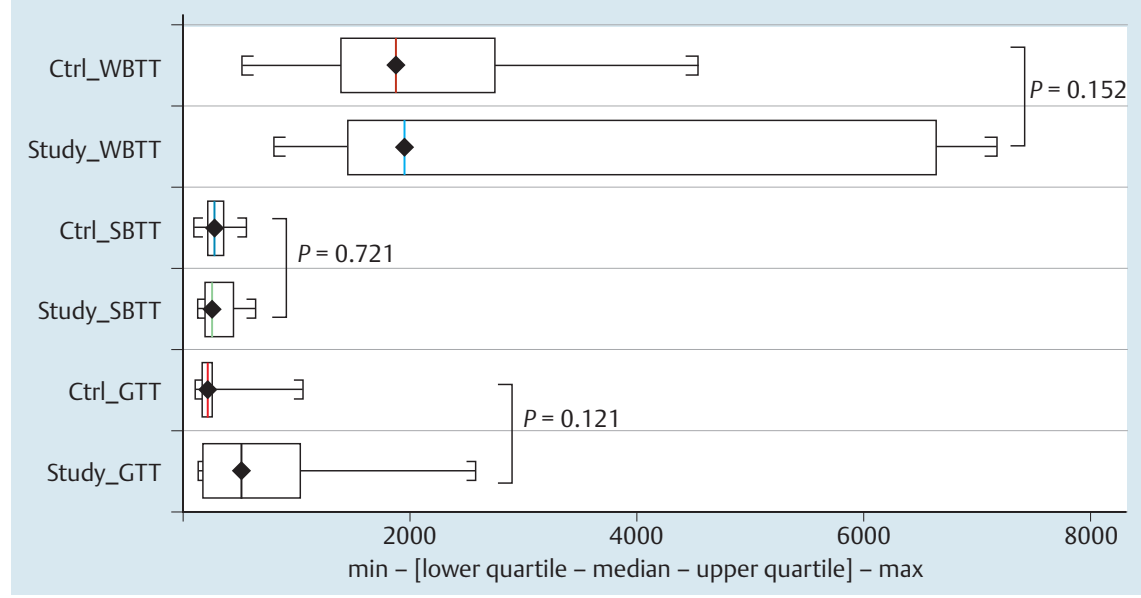

Fig. 3 Comparison of transit times between study group and controls.

Abbreviations: Ctrl, controls; GTT, gastric transit time; SBTT, small-bowel transit time; WBTT, whole bowel transit time

Fig. 4 Comparison of motility index between study group and controls.

Abbreviations: Ctrl, controls; duo, duodenum; MI, motility index; SB, small bowel 


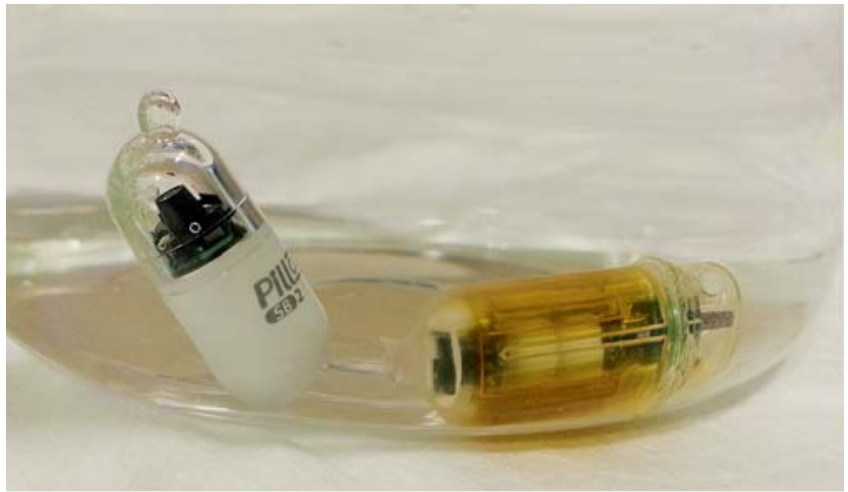

Fig. 5 Floating characteristics of Pillcam SB2 (left) and Smartpill (right) submerged in $400 \mathrm{~mL}$ sterile water for irrigation.

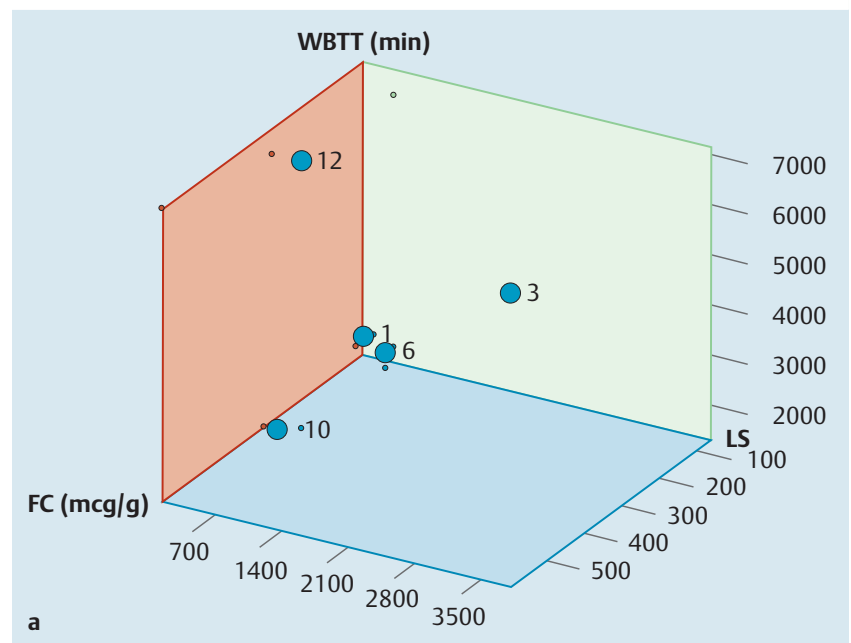

Fig. 6a (see above) Distribution of WBTT, FC and LS for patients in our study for whom the relevant data sets were available. Each plot point represents a patient in our study with the numbers corresponding to patient numbers in $\bullet$ Table 3 .

Abbreviations: FC, fecal calprotectin; LS, Lewis score; WBTT, whole bowel transit time

b Linear regression of $\mathrm{FC}$ against motility indices for patients in our study for whom the relevant data sets were available.

c Linear regression of LS against motility indices for patients in our study for whom the relevant data sets were available.

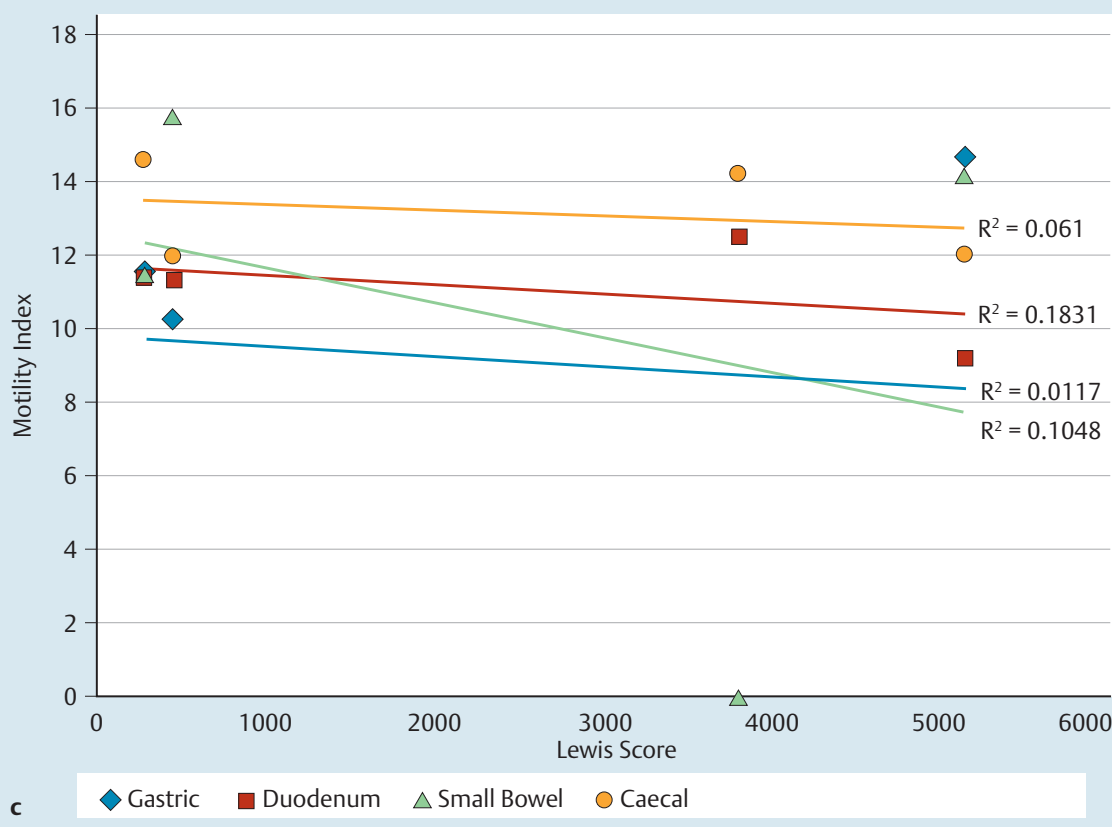


$[2,13]$, especially when first-line investigations are inconclusive. Compared to the traditional method of assessing gastrointestinal motility with scintigraphy/radio-opaque markers, WMC is not associated with any radiation exposure. Concurrent use of SBCE and WMC shows how multimodal information can provide information not only on the mucosal appearances of patients with $C D$ but also physiological motility data. However, that needs to be balanced against the risk of capsule retention, a feared complication in patients with CD. In our study, there was one case of stomach retention of the capsule, which occurred despite patency check with follow-up plain abdominal x-ray where the patency capsule had been reported to be in the large bowel. Limited CT scanning post-patency may be more useful in these patients [14]. Our patients had significantly longer transit times compared to the controls $(P<0.05$ for all parameters measured) ( $\bullet$ Table 4$)$. However, statistical significance should be interpreted with caution given the small sample size. Other limitations of this pilot study include potential selection bias, as patients with significant SB inflammation were excluded due to fear of capsule retention, and the SmartPill ${ }^{\circledR}$ signal loss (resulting in incomplete data sets in $5 / 10$ completed WMC examinations). It is not clear if this is due to technological limitations or whether the concurrent use (4 hours apart) of two capsules caused some radiofrequency interference $[1,5,6]$. Furthermore, the complexity of the WMC data did not allow meaningful correlation with other parameters such as FC and LS. This can be seen in other studies that have tried to explore the relationship between LS and FC in patients with SB CD [15].

\section{Take home messages}

- Physiological data obtained from the use of the SmartPill ${ }^{\circledR}$ could be of value in conjunction with 'conventional' SBCE to shed more light in the pathophysiology of $\mathrm{CD}$ and perhaps assist in patient management. However, to better help clinicians to understand and maximize use of the motility information, the development of a simplified interpretation system is necessary.

- Despite concerns about capsule retention in patients with $C D$, our study suggests that the SmartPill ${ }^{\circledR}$ seems generally safe for use in these patients, although use of a patency capsule is recommended beforehand.

Competing interests: Dr. Koulaouzidis has received a research grant from ESGE Given Imaging.

\section{Acknowledgements}

The study was supported by a defined grant by Given ${ }^{\circledR}$ Imaging Ltd (ESGE- Given ${ }^{\circledR}$ Imaging Research grant 2011).

\section{References}

1 Tran K, Brun R, Kuo B. Evaluation of regional and whole gut motility using the wireless motility capsule: relevance in clinical practice. Therap Adv Gastroenterol 2012; 5: 249-560

2 Wang YT, Mohammed SD, Farmer $A D$ et al. Regional gastrointestinal transit and $\mathrm{pH}$ studied in 215 healthy volunteers using the wireless motility capsule: influence of age, gender, study country and testing protocol. Aliment Pharmacol Ther 2015; 42: 761 - 772

3 Rao SSC, Camilleri M, Haler WL et al. Evaluation of gastrointestinal transit in clinical practice: position paper of the American and European Neurogastroenterology and Motility Societies. Neurogastroenterol Motil 2011; 23: 8-23

4 Bai JP, Burckart GJ, Mulberg AE. Literature Review of Gastrointestinal Physiology in the Elderly, in Pediatric Patients, and in Patients with Gastrointestinal Diseases. J Pharm Sci 2015

5 Wang A, Banerjee S, Barth BA et al. Wireless capsule endoscopy. Gastrointest Endosc 2013; 78: 805-15

6 Koulaouzidis A, Plevris JN. Investigating the small-bowel: a brief and concise update. Glob J Gastroenterol Hepatol 2013; 1: 18-28

7 Kopylov U, Papageorgiou NP, Nadler M et al. Head or tail: the orientation of the small bowel capsule endoscope movement in the small bowel. Dig Dis Sci 2012; 57: 694-698

8 Koulaouzidis A, Douglas S, Plevris JN. Heads or tail orientation in smallbowel capsule endoscopy: 2 capsule models with 2 reviewers. Dig Dis Sci 2012; 57: $1102-1104$

9 Van Assche G, Dignass A, Panes J et al. The second European evidencebased Consensus on the diagnosis and management of Crohn's disease: Definitions and diagnosis. J Crohns Colitis 2010; 4: 7-27

10 Fireman Z, Mahajna E, Broide E et al. Diagnosing small bowel Crohn's disease with wireless capsule endoscopy. Gut 2003; 52: 390-392

11 Froehlich JM, Waldherr C, Stoupis C et al. MR motility imaging in Crohn's disease improves lesion detection compared with standard MR imaging. Eur Radiol 2010; 20: 1945 - 1951

12 Nobrega AC, Ferreira BR, Oliveira GJ et al. Dyspeptic symptoms and delayed gastric emptying of solids in patients with inactive Crohn's Disease. BMC Gastroenterol 2012; 7: 175

13 Jones MP, Bratten JR. Small intestinal motility. Curr Opin Gastroenterol 2008; 24: $164-172$

14 Assadsangabi A, Blakeborough A, Drew K et al. Small bowel patency assessment using the patency device and a novel targeted (limited radiation) computed tomography-based protocol. J Gastroenterol Hepatol 2015; 30: $984-989$

15 Koulaouzidis A, Douglas S, Plevris JN. Lewis score correlates more closely with fecal calprotectin than Capsule Endoscopy Crohn's Disease Activity Index. Dig Dis Sci 2012; 57: 987-993 